\title{
Photonics Society of Poland celebrates the International Year of Light
}

\author{
Tomasz R. Woliński ${ }^{* 1,2}$ \\ ${ }^{1}$ Faculty of Physics, Warsaw University of Technology, Koszykowa 75, 00-662 Warszawa \\ ${ }^{2}$ Photonics Society of Poland President
}

Received June 30, 2015; accepted June 30, 2015; published June 30, 2015

\begin{abstract}
The current issue of the Photonics Letters of Poland addresses the celebration of the International Year of Light by the photonics community in Poland.
\end{abstract}

The Photonics Society of Poland (PSP), which has been editing the Photonics Letters of Poland for the last 7 years in close collaboration with SPIE, celebrates this year together with the whole optics/photonics community worldwide - the International Year of Light and Lightbased Technologies (IYL 2015). IYL 2015 is endorsed by a number of international scientific unions and the International Council of Science, and has more than 100 partners from more than 85 countries including the PSP.

The first official event was the Opening Ceremony held at UNESCO HQ in Paris on January 19-20, 2015. Poland was represented in Paris by 4 PSP members (Małgorzata Kujawińska, Michał Makowski, Tomasz Woliński, and Weronika Zaperty). This was the beginning of a year-long series of activities all over the world. On the IYL website (www.light2015.org) you can access the calendar of events/activities organized worldwide and also in Poland.

On April 8-9, 2015, the Photonics Society of Poland (www.photonics.pl) organized in Warsaw its $3^{\text {rd }}$ Symposium combined with OPTONexpo, $3^{\text {rd }}$ International Trade for Optoelectronics and Photonics. The Symposium gathered more than 100 PSP members, local government officials, trade exhibitors as well as many students and young people interested in photonics and light-based technologies. The Symposium program included invited lectures of such prominent international speakers as:

- Dr. Eugen Arthurs, CEO SPIE, Photonics and Politics,

- Dr. Francesco Baldini, 2015 SIOF President (Italy), Optical biosensing in biomedical field,

- Prof. John Dudley, IYL 2015 President, 1000 years of optics, 50 years of solitons

- Prof. Gerald Farrell, Dublin Institute of Technology (Ireland), Optical Fiber Sensing: Sensing solutions from the macro world to the micro world,
- Dr. Torsten Mehlhorn, Fraunhofer HHI (Berlin), Transnational optical cooperation for science and industrial partnership between Poland and Germany,

- $\quad$ Prof. Philip Russell, 2015 OSA President, Gas, glass \& light: Enhancing light-matter interactions in microstructured fibres,

- Prof. Toyohiko Yatagai, 2015 SPIE President (Japan), Holographic Optical Memory - challenge again.

Two interesting lectures were also delivered by young and talented PSP members: Michał Makowski (Picoprojection based on real-time computer holography) and Grzegorz Soboń (Ultrafast fiber lasers based on graphene and other nanomaterials).

The PSP Gala took place in the evening of April 8, 2015 in a beautiful and historical building of the Faculty of Physics, Warsaw Univ. of Technology. The students presenting posters at the PSP Symposium were awarded by OSA and SPIE students prizes handed by the presidents of both societies: Philip Russell (OSA) and Toyohiko Yatagai (SPIE). The winners of the OSA student prizes were Arkadiusz Kuś and Paweł Jung (Warsaw Univ. of Technology), whereas the SPIE student prizes were granted to: Paulina Pura-Pawlikowska, (Military Univ. of Technology, $1^{\text {st }}$ prize): Maciej Kraszewski, (Gdansk Univ. of Technology, $2^{\text {nd }}$ prize), and Izabela Ducin, (Warsaw Univ. of Technology, $3^{\text {rd }}$ prize).

The highest PSP award, i.e. Prof. Maksymilian Pluta's Award 2015, was presented to Eugene Arthurs, SPIE CEO In recognition of his outstanding and continuous support enabling the first steps of a new e-journal Photonics Letters of Poland.

Prof. Jan Szmidt, Rector of the Warsaw University of Technology presented also to Eugen Arthurs, Philip Russell, and Toyohiko Yatagai Gold Medals of 100 Years Revival of the Warsaw University of Technology.

The current PLP issue contains selected photos from $3^{\text {rd }}$ PSP Symposium as well as selected papers submitted to our e-journal in the first months of the IYL 2015.

\footnotetext{
*E-mail: wolinski@if.pw.edu.pl
} 
Selected photos from "Third Symposium of the Photonics Society of Poland" - more information at http://photonics.pl
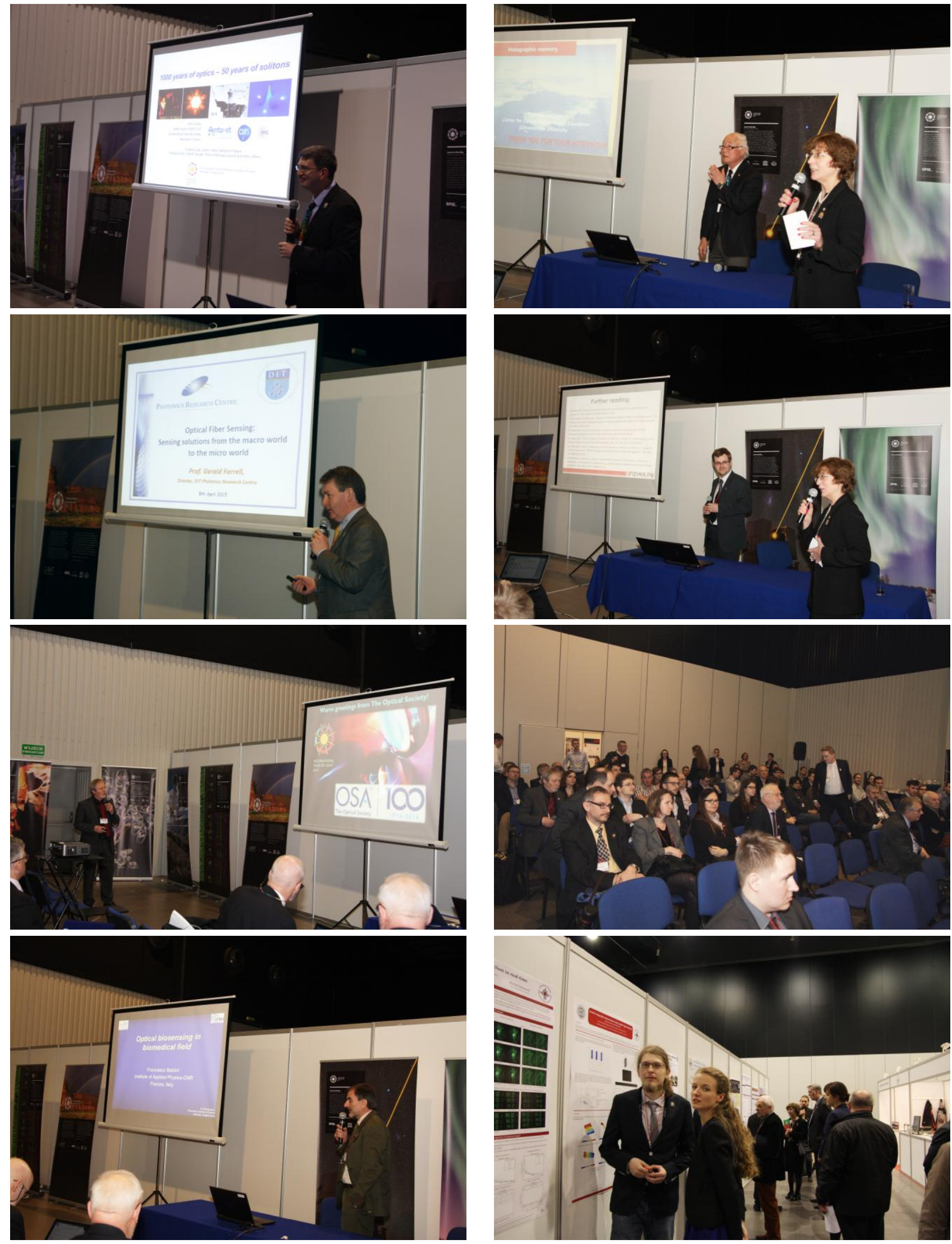

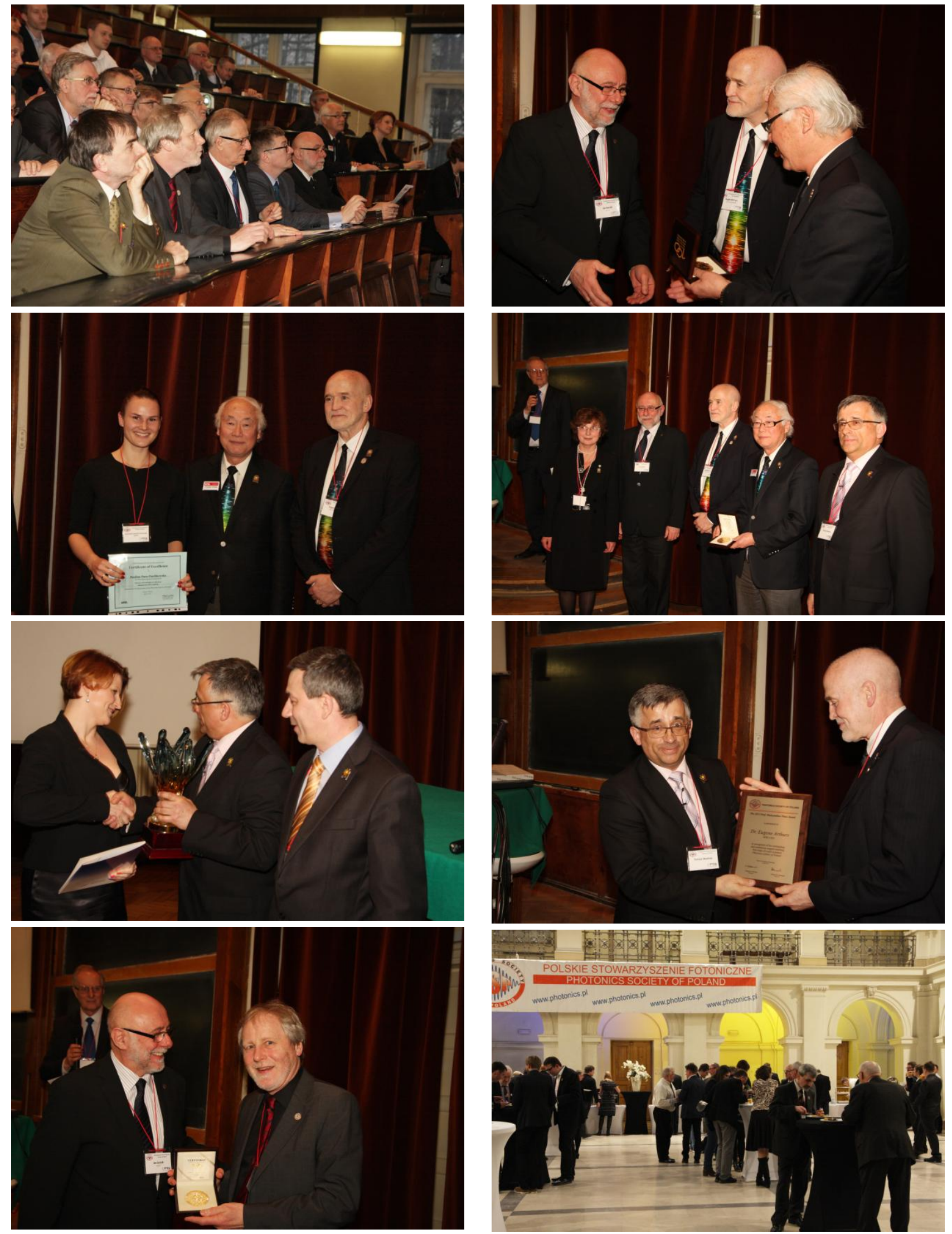